\title{
The Prevalence and Clinical Significance of Presymptomatic COVID-19 Patients: How We Can be One Step Ahead in Mitigating a Deadly Pandemic
}

\section{Juen Kiem Tan}

Pusat Perubatan Universiti Kebangsaan Malaysia https://orcid.org/0000-0001-8904-9799

\section{Dalleen Leong}

Pusat Perubatan Universiti Kebangsaan Malaysia

\section{Hemalatha Munusamy}

Pusat Perubatan Universiti Kebangsaan Malaysia

Nor Hazwani Zenol Ariffin

Pusat Perubatan Universiti Kebangsaan Malaysia

\section{Najma Kori}

Pusat Perubatan Universiti Kebangsaan Malaysia

\section{Rozita Hod}

Pusat Perubatan Universiti Kebangsaan Malaysia

Petrick Periyasamy ( $\sim$ petrick.periyasamy@gmail.com )

Pusat Perubatan Universiti Kebangsaan Malaysia

\section{Research article}

Keywords: Coronavirus disease 2019, COVID-19, SARS-CoV-2, presymptomatic

Posted Date: September 18th, 2020

DOI: https://doi.org/10.21203/rs.3.rs-60558/v1

License: (c) (i) This work is licensed under a Creative Commons Attribution 4.0 International License. Read Full License

Version of Record: A version of this preprint was published on March 9th, 2021. See the published version at https://doi.org/10.1186/s12879-021-05849-7. 


\section{Abstract}

Presymptomatic COVID-19 patients have been identified as a major stumbling block in efforts to break the chain of transmission. Studies on temporal dynamics of its shedding suggests it peaks 1-2 days prior to any symptom onset. Therefore, a large proportion of patients are actively spreading the disease unknowingly whilst undetected. However, lengthy lockdowns and isolation leads to a host of socioeconomic issues and are impractical. Conversely, there exists no study describing this group and their clinical significance despite their key role in disease transmission. As a result, we devised a study to look at the prevalence of presymptomatic patients with COVID-19 and subsequently, identify early indicators of infection through demographic information, biochemical and radiological abnormalities which would allow early diagnosis and isolation. In addition, we will look into the clinical significance of this group and their outcome; if it differs from asymptomatic or symptomatic patients. Our analysis shows a higher proportion of presymptomatic patients with atypical symptoms like chest pain while symptomatic patients commonly present with respiratory symptoms like cough and shortness of breath. Besides that, there were more females presenting as presymptomatic patients and receiving treatment compared to males and this was found to be statistically significant. Otherwise, we were not able to identify other statistically significant markers suggesting a patient is presymptomatic. As we have little means of identifying these silent spreaders, it highlights further the importance of general measures implemented to stop COVID-19 transmission like social distancing, face mask, and widespread testing.

\section{Highlights}

1. $21.6 \%$ of patients admitted were presymptomatic and could have transmitted the disease prior to symptom onset.

2. Significantly more females were presymptomatic on presentation compared to males.

3. No significant biochemical or radiological findings to suggest patients may be presymptomatic

\section{Introduction}

The start of the new decade would undoubtedly be remembered as a time when a global pandemic had brought most parts of the world to a complete standstill. The coronavirus disease 2019 (COVID-19) first reported six months ago in Wuhan, China has since infected five million globally, claiming over three hundred thousand lives at the time of writing. The first two confirmed cases in Malaysia were announced in February 4th 2020; the first an elderly Chinese national who had arrived in mid-January, and the second, a local middle-aged gentleman who had just returned from Singapore where he attended an international conference with many foreign delegates. Both patients only presented to healthcare centres at the onset of clinical symptoms. ${ }^{1}$

Since then, several clusters involving overseas travellers, repatriated Malaysians and most notably a religious gathering attended by roughly 16,000 local and international delegates had led to almost 7,000 confirmed cases and 114 deaths reported. ${ }^{2,3}$ The country's mortality rate of $1-2 \%$ is disproportionate to the global rate which stands at almost $7 \% .{ }^{4}$ This is largely due to the adequacy of critical care beds to accommodate patients as well as concerted efforts by the health ministry in containing the disease at a relatively early stage.

In response, most countries have implemented movement restriction orders or lockdowns to prevent disease transmission to great effect. In Malaysia, restrictions were announced on 16th March 2020 limiting the general public from travelling further than 10 kilometres from their residence, mandatory closure of all premises excluding those 
involved in essential services (e.g. pharmacies, food supply, etc.), halting entry of all tourists as well as a 14-day quarantine order for Malaysians returning from overseas travels. ${ }^{5}$

Presymptomatic is defined as the presence of illness before the appearance of symptom. Published data have shown that COVID-19 is transmissible via presymptomatic patients, as well as growing data suggesting asymptomatic transmission, forcing healthcare providers to formulate various strategies in disease control. ${ }^{6-8} \mathrm{He}$ and Lau et al. had demonstrated that the highest viral load in throat swabs are at symptom onset and may have peaked 1-2 days earlier in presymptomatic stage, while pooled data of 1251 cases suggests that presymptomatic infectious rates could be as high as $68 \%$ of total infections. ${ }^{9,10}$ Therefore, failing to address this population would lead to failure of containment and mitigation of the pandemic.

As a result, we acknowledge that movement restrictions may not be a feasible long-term plan but on the other hand, failing to enforce social distancing amongst the public would lead to irrepressible infection rates. Therefore, in this study, we hope to relook at our local demographics, presentations and baseline investigations, observing for possible patterns or early abnormalities that may suggest patients infected with COVID-19 may be at presymptomatic stage, hoping to get one step ahead of the pandemic and minimising its socioeconomic impact.

\section{Methods}

We carried out a retrospective single centre study between 17th March 2020 and 26th April 2020 at the National University of Malaysia Medical Centre. Our centre is based in Cheras, one of four red zone districts in Kuala Lumpur since 6th April 2020 when it recorded more than 41 new confirmed case per day. Participants recruited were confirmed COVID-19 patients referred for tertiary care from primary and private healthcare centres as well as quarantine facilities having tested positive via qualitative reverse transcription polymerase chain reaction (RT-PCR) from nasopharyngeal and/or oropharyngeal swab, with cycle threshold value set at 45 , targeting the RNA-dependent RNA polymerase (RdRp) and envelope (E) genes.

Data were sourced via our centre's medical records department manually as well as additional history from patients still admitted and recovering as required. Demographic details collected include age, gender, background medical illnesses, cigarette smoking, alcohol consumption, presence of symptoms prior to and/or during admission, blood abnormalities, chest $x$-ray and/or chest computed tomography changes, treatment given and classification of case to presymptomatic, symptomatic or true asymptomatic with further note on atypical or paucisymptomatic presentation.

In Malaysia, patients with COVID-19 are categorised to five clinical classes; 1-asymptomatic, 2-symptomatic, 3evidence of pneumonia, 4-oxygen supplement requirement, and 5- intubated and/or multiorgan failure. The addition of ' $A$ ' and ' $B$ ' is to signify afebrile and febrile patients. These details including the highest documented modified early warning score (MEWS); which is used to decide frequency of vital sign monitoring; were documented.

Patients were classified as symptomatic if they present with symptoms prior to a positive test result and true asymptomatics for those who had developed no symptoms throughout the infection. ${ }^{11}$ Patients are labelled presymptomatic if they were asymptomatic prior to testing but developed symptoms within 14 days after testing based on studies showing its incubation period extending to 15 days. However, we also included those who presented with symptoms beyond that as similar studies have suggested that 101 out of every 10,000 cases may develop symptoms beyond 14 days. ${ }^{12,13}$ They were further classified to typical symptoms; fever, cough, shortness of breath or exertional dyspnea including bendopnea (previously coined for heart failure but significant among our demographics; 
representing a Muslim majority), atypical symptoms (chest pain, headache, gastrointestinal complaints, etc.) or paucisymptomatic having 1-2 minor symptoms. ${ }^{14-16}$

Statistical analysis was performed with SPSS Version 26.0 statistic software package. To summarise the data, we used descriptive statistics in addition to tabulating the variables and corresponding values for reference. Variables between each group of presymptomatic, symptomatic and true asymptomatic were associated via Chi square test or Fisher's exact test, accepting a $p$ value of $<0.05$ as significant.

\section{Results}

A total of 205 patients with COVID-19 have been treated at our centre. We included 199 patients in our study, having excluded six patients as key data were lacking in their medical records. The mean age of patients was $34 \pm 16$ (SD) years ranging from 2 to 91 years old. A male preponderance was observed making up $73.9 \%$ of patients. 109 patients body mass index (BMI) were recorded with a mean of $25.3 \pm 6.3$ (SD) ranging from 15 to 52 . Besides that, 53 patients (26.6\%) in our cohort have comorbidities; mainly hypertension, diabetes mellitus and dyslipidemia. Interestingly, there were no patients with background chronic obstructive pulmonary disease.

Out of 124 entries regarding cigarette smoking, 15 patients were active cigarette smokers while 8 are reformed smokers. Only 7 out of 62 participants consume alcoholic beverages. Eventually, 196 patients were discharged well, one patient with multiple comorbidities succumbed to the disease and two patients were transferred out to a nearby hospital catering for infectious diseases prior to our centre's active management of COVID-19 patients. Our sample's demographic details are summarised in Table 1. 
Table 1

Demographic information of our cohort of COVID-19 patients $(\mathrm{n}=$ 199)

\begin{tabular}{|c|c|}
\hline demographics & n (\%) \\
\hline \multicolumn{2}{|l|}{ Age (years old) } \\
\hline$<10$ & $1(0.5)$ \\
\hline $10-19$ & 27 (13.6) \\
\hline $20-29$ & 78 (39.2) \\
\hline $30-39$ & $34(17.1)$ \\
\hline $40-49$ & $24(12.1)$ \\
\hline $50-59$ & $15(7.5)$ \\
\hline $60-69$ & $12(6)$ \\
\hline $70-79$ & $6(3)$ \\
\hline $80-89$ & $1(0.5)$ \\
\hline$>90$ & $1(0.5)$ \\
\hline \multicolumn{2}{|l|}{ GENDER } \\
\hline MALE & 147 (73.9) \\
\hline FEMALE & $52(26.1)$ \\
\hline \multicolumn{2}{|l|}{ BMI } \\
\hline$<18.5$ & $7(6.4)$ \\
\hline $18.5-22.9$ & $40(36.7)$ \\
\hline $23-26.9$ & $32(29.4)$ \\
\hline$>27$ & $30(27.5)$ \\
\hline \multicolumn{2}{|l|}{ SmOKING } \\
\hline ACTIVE & $15(12.1)$ \\
\hline NON-SMOKER & 101 (81.5) \\
\hline REFORMed & $8(6.4)$ \\
\hline ALCOHOL & $7(11.3)$ \\
\hline Comorbidites & $53(26.6)$ \\
\hline DM & 13 \\
\hline Hypertension & 26 \\
\hline Dyslipidaemia & 10 \\
\hline IHD & 4 \\
\hline
\end{tabular}




\begin{tabular}{|ll|}
\hline demographics & $\mathbf{n}(\%)$ \\
\hline CKD & 3 \\
\hline COPD & 0 \\
Others & 29 \\
\hline NO COMORBIDS & $146(73.4)$ \\
\hline Outcome & \\
\hline DISCHARGED & $196(98.5)$ \\
\hline DECEASED & $1(0.5)$ \\
\hline TRANSFER OUT & $2(1)$ \\
\hline
\end{tabular}

From our data, most patients (95\%) were diagnosed through screening (via contact tracing, high risk groups) and only 10 patients (5\%) were detected due to presenting symptoms. Besides that, $31(15.6 \%)$ had history of recent overseas travel. Cough and fever were the most prevalent symptom affecting $45(22.6 \%)$ and $40(20.1 \%)$ patients respectively. In addition, non-specific and pleuritic chest pain were the most common atypical symptoms affecting 21 patients (10.5\%) followed by headache and anosmia. Atypical symptoms like headache, giddiness, behavioural changes were more commonly seen in the elderly population. Table 2 summarises the clinical manifestations present on admission as well as during admission. 
Table 2

Clinical manifestation upon presentation and during hospital admission ( $\mathrm{n}=199)$

\begin{tabular}{|c|c|c|c|c|}
\hline Parameters / symptoms & symptoms on presentation & symptoms during admission & total & \\
\hline & $\mathrm{n}=53(\%)$ & $\mathrm{n}=43(\%)$ & $n=96(\%)$ & $\mathrm{p}$-value \\
\hline Cough & $32(16.1)$ & $13(6.5)$ & 45 & $0.019 *$ \\
\hline Productive & $10(5)$ & $1(0.5)$ & 11 & - \\
\hline Breathlessness & $11(5.5)$ & $5(2.5)$ & 16 & 0.059 \\
\hline $\mathrm{T}<37.8$ & $25(12.6)$ & $2(1.0)$ & 27 & 0.704 \\
\hline $\mathrm{T}>37.8$ & $12(6)$ & $1(0.5)$ & 13 & 0.551 \\
\hline Headache & $6(3)$ & $1(0.5)$ & 7 & 0.791 \\
\hline Giddiness & $2(1)$ & $0(0)$ & 2 & 0.881 \\
\hline Lethargy & $5(2.5)$ & $0(0)$ & 5 & 0.825 \\
\hline Body Weakness & $0(0)$ & $1(0.5)$ & 1 & 0.482 \\
\hline Anosmia & $11(5.5)$ & $0(0)$ & 11 & 0.550 \\
\hline Low Glasgow Coma Scale & $1(0.5)$ & $0(0)$ & 1 & 0.360 \\
\hline Nausea & $1(0.5)$ & $2(1.0)$ & 3 & 0.345 \\
\hline Vomiting & $0(0)$ & $1(0.5)$ & 1 & 0.482 \\
\hline Abdominal Pain & $3(1.5)$ & $3(1.5)$ & 6 & 0.113 \\
\hline Rash & $0(0)$ & $0(0)$ & 0 & - \\
\hline Diarrhoea & $4(2)$ & $6(3.0)$ & 10 & 0.831 \\
\hline Chest Pain & $9(4.5)$ & $12(6)$ & 21 & $0.005^{\star}$ \\
\hline Sore Throat & $17(8.5)$ & $6(3.0)$ & 23 & 0.385 \\
\hline Rhinorrhoea & $20(10.1)$ & $3(1.5)$ & 23 & $0.012^{*}$ \\
\hline Myalgia / Arthralgia & $5(2.5)$ & $1(0.5)$ & 6 & 0.336 \\
\hline
\end{tabular}

Majority of our samples were clinical category one; 93 patients (46.7\%), followed by 79 patients (39.7\%) with category two, 22 patients $(11.1 \%)$ with category 3,3 and 2 patients respectively with category 4 and 5 . The distribution of our patient's clinical category is illustrated in Fig. 1. In addition, the highest MEWS documented were score 1 and 2 with $157(79.3 \%)$ and $32(16.2 \%)$ respectively.

In terms of blood abnormalities, 50 (25.1\%) patients had blood abnormalities on admission while $55(27.6 \%)$ patients in total had abnormalities during admission. The most common abnormality noted was raised liver transaminases. Notably, one quarter of all patients had bilirubin levels at the upper limit of normal at some point during admission regardless of symptoms. All patients had chest $\mathrm{X}$-rays with 30 patients demonstrating radiological abnormalities including peripheral air space opacity and/or consolidation. 44 patients had computed tomography of the thorax 
demonstrating peripheral opacity or consolidation in only 20 patients. 45 patients were given medications during their stay; 43 given hydroxychloroquine, 14 administered azithromycin, 4 given kaletra, 2 on interferon and one given tocilizumab.

Based on our sample, 43 (21.6\%) patients were presymptomatic, 53 (26.6\%) were symptomatic while 103 (51.8\%) were true asymptomatics. There were 9 paucisymptomatic patients each in the symptomatic and presymptomatic groups while there were $10(23.3 \%)$ and $5(9.4 \%)$ patients presenting with atypical symptoms in the presymptomatic and symptomatic group respectively. Presymptomatic patients in our cohort presented with symptoms from day 1 to 14 of admission with a mean of $4 \pm 2.69$ (SD) day of admission and $7.37 \pm 4.32$ (SD) days after first positive COVID19 RT-PCR test with a range of 1 to 24 days. Three outliers manifested symptoms beyond 14 days; 2 at day 17 and one at day 24. Figure 2 demonstrates the different clinical classification in our cohort.

Upon comparing both groups, there was a higher proportion of symptomatic patients with cough $(p=0.019)$ and rhinorrhoea $(p=0.012)$ that was found to be significant. On the other hand, chest pain was more prevalent in the presymptomatic group $(p=0.005)$. The proportion of males and females among the different clinical groups were significantly different $(p=0.019)$ with a larger percentage of females in the presymptomatic group compared to males. Also, more females were started on treatment; majority on hydroxychloroquine; compared to the opposite sex $(p=0.016)$. Further analysis between genders did not show any significant association with regards to blood and chest x-ray abnormalities.

Besides that, there were four patients with clinical category four and above in the symptomatic group with only one in the presymptomatic group with category four. A larger proportion of patients in the symptomatic group had higher overall MEWS and this was statistically significant $(p=0.023)$. With regards to the time from positive to negative COVID-19 RT-PCR, the mean day till negative swab was $16.42 \pm 4.32$ (SD) day of illness. The mean day of illness of negative swabs from presymptomatic, symptomatic and true asymptomatic groups were 17, 18, and 15 days respectively. However, the findings were not statistically significant to suggest the symptomatic groups had a longer duration of positivity ( $p$-value $=0.293$ ).

Otherwise, no significant difference was observed related to categories, smoking history, blood abnormalities, and radiological findings among patients with different clinical groups. Table 3 summarises the comparison of the different clinical groups with multiple variables while table 4 compare the variables between genders. 
Table 3

Comparing presymptomatic, symptomatic and true asymptomatic group $(n=199)$ of patients with COVID-19

\begin{tabular}{|c|c|c|c|c|c|c|}
\hline & & $\begin{array}{l}\text { PRESYMPTOM- } \\
\text { ATIC } \\
n=43(\%)\end{array}$ & $\begin{array}{l}\text { SYMPTOMATIC } \\
\mathrm{n}=53(\%)\end{array}$ & $\begin{array}{l}\text { TRUE } \\
\text { ASYMPTOMATIC } \\
n=103(\%)\end{array}$ & $\begin{array}{l}\text { TOTAL } \\
n= \\
199\end{array}$ & p- \\
\hline \multirow[t]{2}{*}{ GENDER } & FEMALE & $18(34.6)$ & $14(26.9)$ & $20(38.5)$ & 52 & $0.019 *$ \\
\hline & MALE & $25(17.0)$ & $39(26.5)$ & $83(56.5)$ & 147 & \\
\hline \multirow[t]{5}{*}{ HIGHESTMEWS } & 0 & $1(50)$ & $0(0)$ & $1(50)$ & 2 & \\
\hline & 1 & $34(21.7)$ & $34(21.7)$ & $89(56.6)$ & 157 & \\
\hline & 2 & $5(15.6)$ & $15(46.9)$ & $12(37.5)$ & 32 & $0.023^{*}$ \\
\hline & 3 & $3(50)$ & $3(50)$ & $0(0)$ & 6 & \\
\hline & 4 & $0(0)$ & $0(0)$ & $1(100)$ & 1 & \\
\hline \multirow{8}{*}{$\begin{array}{l}\text { CATEGORY } \\
\text { AFTER RE- } \\
\text { EVALUATION }\end{array}$} & 1 & $0(0)$ & $1(1.1)$ & $92(98.9)$ & 93 & \\
\hline & $2 \mathrm{~A}$ & $27(45.8)$ & $32(54.2)$ & $0(0)$ & 59 & \\
\hline & $2 \mathrm{~B}$ & $8(40)$ & $12(60)$ & $0(0)$ & 20 & \\
\hline & $3 A$ & $5(25)$ & $4(20)$ & $11(55)$ & 20 & - \\
\hline & $3 B$ & $2(100)$ & $0(0)$ & $0(0)$ & 2 & \\
\hline & $4 \mathrm{~A}$ & $1(50)$ & $1(50)$ & $0(0)$ & 2 & \\
\hline & $4 \mathrm{~B}$ & $0(0)$ & $1(100)$ & $0(0)$ & 1 & \\
\hline & 5 & $0(0)$ & $2(100)$ & $0(0)$ & 2 & \\
\hline \multirow[t]{3}{*}{ SMOKER } & NO & $24(23.8)$ & $20(19.8)$ & $57(56.4)$ & 101 & \\
\hline & REFORMED & $1(12.5)$ & $4(50)$ & $3(37.5)$ & 8 & 0.359 \\
\hline & YES & $2(13.3)$ & 5 (33.3) & 8 (53.3) & 15 & \\
\hline \multirow{2}{*}{$\begin{array}{l}\text { BLOOD } \\
\text { ABNORMALITIES } \\
\text { ON ADMISSION }\end{array}$} & NO & $33(22.1)$ & $38(25.5)$ & 78 (52.3) & 149 & 0.817 \\
\hline & YES & $10(20)$ & $15(30)$ & $25(50)$ & 50 & \\
\hline \multirow{2}{*}{$\begin{array}{l}\text { BLOOD } \\
\text { ABNORMALITIES } \\
\text { DURING STAY }\end{array}$} & NO & $32(22.2)$ & $35(24.3)$ & $77(53.5)$ & 144 & 0.485 \\
\hline & YES & $11(20)$ & $18(32.7)$ & $26(47.2)$ & 55 & \\
\hline \multirow[t]{3}{*}{ BLOOD INDICES } & $\mathrm{CBC}$ & $2(1)$ & $1(0.5)$ & $3(1.5)$ & 6 & 0.442 \\
\hline & $\mathrm{RP}$ & $4(2)$ & $6(3)$ & $10(5)$ & 20 & 0.487 \\
\hline & LFT & $11(5.5)$ & $20(10)$ & $24(12)$ & 55 & 0.119 \\
\hline \multirow{2}{*}{$\begin{array}{l}\text { RADIOLOGICAL } \\
\text { INVESTIGATIONS }\end{array}$} & X-RAY & $10(5)$ & $9(4.5)$ & $11(5.5)$ & 30 & 0.126 \\
\hline & $\begin{array}{l}\text { CT THORAX } \\
\text { PERFORMED }\end{array}$ & $8(4)$ & $11(5.5)$ & $25(12.6)$ & 44 & 0.748 \\
\hline
\end{tabular}




\begin{tabular}{|c|c|c|c|c|c|c|}
\hline & & $\begin{array}{l}\text { PRESYMPTOM- } \\
\text { ATIC } \\
n=43(\%)\end{array}$ & $\begin{array}{l}\text { SYMPTOMATIC } \\
n=53(\%)\end{array}$ & $\begin{array}{l}\text { TRUE } \\
\text { ASYMPTOMATIC } \\
\mathrm{n}=103(\%)\end{array}$ & $\begin{array}{l}\text { TOTAL } \\
n= \\
199\end{array}$ & $\begin{array}{l}\text { p- } \\
\text { VALUE }\end{array}$ \\
\hline $\begin{array}{l}\text { NEGATIVE PCR } \\
\text { BASED ON DAY } \\
\text { OF ILLNESS }\end{array}$ & MEAN & 17 DAYS & 18 DAYS & 15 DAYS & $\begin{array}{l}16.42 \\
\text { DAYS }\end{array}$ & 0.293 \\
\hline
\end{tabular}

Table 4

Statistical comparison between genders and clinical variables in our cohort of COVID19 patients

\begin{tabular}{|llll|}
\hline VARIABLES & MALE (\%) & FEMALE (\%) & p-VALUE \\
& $\mathrm{n}=147$ & $\mathrm{n}=52$ & \\
\hline BLOOD ABNORMALITIES ON ADMISSION & $40(27.2)$ & $10(19.2)$ & 0.254 \\
\hline BLOOD ABNORMALITIES DURING STAY & $41(27.9)$ & $14(26.9)$ & 0.893 \\
\hline CHEST X-RAY ABNORMALITY & $20(13.6)$ & $10(19.2)$ & 0.330 \\
\hline TREATMENT GIVEN & $27(18.4)$ & $18(34.6)$ & $0.016^{*}$ \\
\hline *. The Chi-square statistic is significant at the .05 level. & & \\
\hline
\end{tabular}

Lastly, we had a large number of foreign nationals admitted; 59 (29.6\%) patients in total; comprising of Indonesians, Bangladeshis, Pakistanis, Indian and Myanmar nationals. From this diverse demograph, 11 patients each were presymptomatic and symptomatic while 31 were true asymptomatic. Besides that, 4 patients were clinically category 3 but none were ill.

\section{Discussion}

Our study of 199 patients revealed a relatively large proportion of presymptomatic patients; amounting to 41 (21.6\%); interestingly with a female preponderance. This may be related to studies suggesting higher circulating angiotensinconverting enzyme 2 in male patients leading to infection and possibly higher viral loads causing clinical manifestation, but more research is required before jumping into conclusions seeing that a large proportion of male patients were asymptomatic as well. ${ }^{17}$ Conversely, females were initiated on treatment more frequently. This could be explained by the higher proportion of presymptomatic presentation, giving the impression of disease progression during admission. Published data have suggested a higher infection rate and mortality in male patients and in our cohort, we did observe higher admissions and one death among male patients. ${ }^{18}$ However, there are no significant statistical difference in terms of investigation results or ill patients upon comparing both genders.

Apart from that, the typical symptoms of cough and rhinorrhoea were evidently the most frequent symptoms observed in our sample as well. Respiratory symptoms like cough, shortness of breath, sore throat and rhinorrhoea were more common in the symptomatic group likely due to COVID-19 being educated to the public as a respiratory disease as well as being severe enough to prompt them to seek medical advice. Atypical chest pains presented more frequently in the presymptomatic group and whether this may be due to inflammatory responses or viral shedding 
needs to be looked into. ${ }^{19}$ MEWS was generally higher in the symptomatic group as well due to fever and increased respiratory rate as a physiological compensatory mechanism to metabolic acidosis secondary to pyrexia.

Besides that, our data revealed that 5 of our 15 cigarette smokers were clinically category 3 or above with one of them requiring intubation and mechanical ventilation. Reformed smokers, on the other hand, were similar to the nonsmoking group in distribution of clinical category. This correlated with systemic reviews suggesting active cigarette smokers were at higher risk of negative clinical progression. ${ }^{20}$ Otherwise, we were unable to pick up any significant or statistical early abnormalities biochemically or radiologically which may suggest the patient may be in presymptomatic phase.

As a result, this further highlights the difficulty in identifying these 'silent spreaders' who will escape detection despite being at the peak of viral shedding. If the numbers are to be taken literally, over $20 \%$ of infected patients may be actively shedding the virus undetected despite point of entry screenings. However, as keeping the public at home at all times is impractical, additional steps must be taken to contain the disease effectively via primary prevention.

A review on 172 studies revealed that maintaining a physical distance of one meter reduces transmission rates significantly; more so if a distance of two meters and above is kept. ${ }^{21}$ Besides that, the use of face masks resulted in a large reduction in risk of infection; significantly greater with use of 3-ply surgical masks and N95 respirators. However, this would not practical with the global shortage of N95 masks for the time being and should be reserved for high risk professions and aerosol generating procedures as recommended by the Centers for Disease Control and Prevention (CDC). ${ }^{22}$

Droplet precaution also includes frequent hand washing with correct techniques and sufficient duration with soap or alcohol-based sanitizers. Its transmissibility via fomites is well documented and eye or face shields would further curb the spread in public and especially in an outpatient clinic setting. ${ }^{23-25}$ Aside from strictly limiting visitors to healthcare facilities, there should be a movement towards the direction of telemedicine to reduce outpatient numbers without compromising care.

Two other important strategies are contact tracing and mass screening. However, contact tracings effectiveness may be hampered by misinformation and its slow process, in which several 'generations' of disease transmission may have already occurred. In this digital age, applications like 'TraceTogether' and 'CovidSafe' in Singapore and Australia have tremendously increased the speed of tracing with the focus on significant person to person contact recorded via Bluetooth; storing information on mobile phones. ${ }^{26}$ In addition, applications like 'NZ Covid Tracer' and 'MySejahtera' from New Zealand and Malaysia respectively allows users to check in locations via QR codes, negating the need for manual documentation in which stationaries may be shared and allows contact tracing to be rapid in instances where a positive patient may have visited previously. ${ }^{27}$

By now, South Korea's success story with mass screening as its backbone is well documented; testing close to a quarter million people in just one and a half months allowing rapid isolation of those affected. ${ }^{28}$ High risk populations should be frequently screened including nursing centres and establishments in which close contacts are unavoidable like hostels, prisons and detention centres. Malaysia; taking a leaf out of Singapore's book on handling migrant workers; had detected a large proportion of patients by screening documented and undocumented foreign workers as evident in our cohort, making up one third of total patients. ${ }^{29}$ In addition, South Korea have implemented low-contact testing centres allowing nasopharyngeal swabs to be performed from booths and via drive-throughs which is also practiced locally here in government and private healthcare facilities. ${ }^{30}$ 
In efforts to further reduce contact, several large corporations have implemented guidelines allowing employees to work from home whenever possible. ${ }^{31}$ This reduces the risk of transmission but may only be practical for white collar workers. Therefore, to cater to other working classes, countries like Germany have provided financial aid by directly paying a large percentage of the wages of their working class, thereby greatly reducing unemployment and retrenchment with an overall cost benefit of not needing to retrain new workers. ${ }^{32}$

There were several limitations to our study. Firstly, we were not able to assess our cohort of presymptomatic patients' quantitative RT-PCR levels prior and during symptom onset and that would be able to shed light on the temporal dynamics in viral shedding as illustrated by He and Lau et al. The result obtained may support the notion that the peak period of viral shedding occurs 1-2 days prior to symptom onset, increasing infectivity and highlighting the importance of this period. Secondly, as the history was obtained through medical records and clarified with patients, there may be errors in ascertaining the exact date of symptoms and clinical manifestation which might inadvertently lead to patients being classified wrongly. Thirdly, in accordance to our local guidelines, we had repeated swabs at day 13 of illness and if positive, 48 to 72 hours subsequently based on updates in the guidelines. Therefore, we were not consistent in the day of illness we had taken samples in addition to not collecting samples before day 13 when they may already yield a negative result.

\section{Conclusion}

The Covid-19 pandemic, being half a year old still carries a lot of unanswered questions. A large proportion of patients are presymptomatic and capable of spreading the infection without any obvious early indication of illness. While researchers are still coming up with definitive treatments, vaccines, and an ideal rapid test that would aid us in treating and identifying these silent spreaders, we need to buy time by reducing the risk of transmission. Still, lengthy lockdowns have a negative socio-economic impact but nations can replicate countries like Germany and South Korea to name a few who have been able to remain open with little restrictions, minimising the economic impact of the pandemic without compromising healthcare. In the meantime, buzzwords like 'social distancing', 'social responsibility' and 'new normal' must constantly play in the publics' minds to remind us to adopt new practices to keep our community safe and break the chain of transmission.

\section{Declarations}

\section{ETHICS APPROVAL AND CONSENT TO PARTICIPATE}

Ethical approval was obtained via research ethics committee of University Kebangsaan Malaysia and informed consent of data use taken from participants.

\section{COMPETING INTEREST}

The authors declare that they have no competing interests.

\section{FUNDING}

No funding received to declare.

\section{AUTHOR'S CONTRIBUTION}

JK contributed to the formulation of the study, data collection, data analysis and was a major contributor in manuscript writing. DL contributed in the data collection. $\mathrm{HM}$ and $\mathrm{NHZ}$ contributed in manuscript writing. $\mathrm{NK}$ and $\mathrm{RH}$ 
contributed in the data analysis and article review. PP contributed to the idea and formulation of the study, data analysis, and article review. All authors read and approved the final manuscript.

*The raw data collected for this study is saved in SPSS format and may be requested for use by contacting the corresponding author.

\section{ACKNOWLEDGMENT}

The authors would like to thank Dr Michelle Maryanne Tan, Ms Zarina as well as her team at the medical record office and all the staff involved in the management of the pandemic at our center.

\section{References}

1. Foon Fong, L. (2020, February 4). First Malaysian tests positive for Wuhan coronavirus. Retrieved from https://www.thestar.com.my/news/nation/2020/02/04/first-malaysian-tests-positive-for-wuhan-coronavirus.

2. Veena, B. (2020, April 10). Sri Petaling Tabligh gathering remains Msia's largest Covid-19 cluster | New Straits Times. Retrieved from https://www.nst.com.my/news/nation/2020/04/583127/sri-petaling-tabligh-gatheringremains-msias-largest-covid-19-cluster.

3. Ministry of Health Malaysia.. Portal Rasmi Kementerian Kesihatan Malaysia. Retrieved May 16, 2020, from https://www.moh.gov.my/index.php/pages/view/2019-ncov-wuhan.

4. Max, R.. Mortality Risk of COVID-19 - Statistics and Research. Retrieved May 17, 2020, from https://ourworldindata.org/mortality-risk-covid?country=MYS+OWID_WRL.

5. 14-day Movement Control Order begins nationwide on Wednesday | New Straits Times. (2020, March 16). NST Online. Retrieved from https://www.nst.com.my.

6. Arons MM, Hatfield KM, Reddy SC, et al. Presymptomatic SARS-CoV-2 Infections and Transmission in a Skilled Nursing Facility. 2020;382(22):2081-2090.

7. Wei WE, Li Z, Chiew CJ, Yong SE, Toh MP, Lee VJ. Presymptomatic Transmission of SARS-CoV-2 - Singapore, January 23-March 16, 2020. MMWR Morb Mortal Wkly Rep 2020;69:411-415.

8. He D, Zhao S, Lin Q, et al. The relative transmissibility of asymptomatic COVID-19 infections among close contacts. International Journal of Infectious Diseases. 2020;94:145-147.

9. He X, Lau EHY, Wu P, et al. Temporal dynamics in viral shedding and transmissibility of COVID-19. Nature Medicine. 2020;26(5):672-675.

10. Prakash MK. Quantitative COVID-19 infectiousness estimate correlating with viral shedding and culturability suggests 68\% pre-symptomatic transmissions. medRxiv. 2020:2020.2005.2007.20094789.

11. Ministry of Health., Portal Rasmi Kementerian Kesihatan Malaysia: COVID-19 Guidelines. Retrieved May 17, 2020, from https://www.moh.gov.my/index.php/pages/view/2019-ncov-wuhan-guidelines.

12. Lauer SA, Grantz KH, Bi Q, et al. The Incubation Period of Coronavirus Disease 2019 (COVID-19) From Publicly Reported Confirmed Cases: Estimation and Application. Annals of internal medicine. 2020;172(9):577-582.

13. COVID-19 situation reports- no.73. Retrieved May 4, 2020, from https://www.who.int/emergencies/diseases/novel-coronavirus-2019/situation-reports.

14. Thibodeau JT, Turer AT, Gualano SK, et al. Characterization of a novel symptom of advanced heart failure: bendopnea. JACC Heart failure. 2014;2(1):24-31.

15. Nicastri E, D'Abramo A, Faggioni G, et al. Coronavirus disease (COVID-19) in a paucisymptomatic patient: epidemiological and clinical challenge in settings with limited community transmission, Italy, February 2020. 
2020;25(11):2000230.

16. Vetter P, Vu DL, L'Huillier AG, Schibler M, Kaiser L, Jacquerioz F. Clinical features of covid-19. BMJ. 2020;369:m1470.

17. Li M-Y, Li L, Zhang Y, Wang X-S. Expression of the SARS-CoV-2 cell receptor gene ACE2 in a wide variety of human tissues. Infectious Diseases of Poverty. 2020;9(1):45.

18. Jin J-M, Bai P, He W, et al. Gender Differences in Patients With COVID-19: Focus on Severity and Mortality. 2020;8(152).

19. D'Amico F, Baumgart DC, Danese S, Peyrin-Biroulet L. Diarrhea During COVID-19 Infection: Pathogenesis, Epidemiology, Prevention, and Management. Clin Gastroenterol Hepatol. 2020:S1542-3565(1520)30481-X.

20. Vardavas Cl, Nikitara K. COVID-19 and smoking: A systematic review of the evidence. Tob Induc Dis. 2020;18:2020.

21. Chu DK, AkI EA, Duda S, et al. Physical distancing, face masks, and eye protection to prevent person-to-person transmission of SARS-CoV-2 and COVID-19: a systematic review and meta-analysis. The Lancet.

22. Markets, F. (2020, April 7). Global N95 Mask Market is Expected to Reach USD 1897 Million by 2027: Retrieved from https://www.globenewswire.com/news-release/2020/04/07/2012991/0/en/Global-N95-Mask-Market-isExpected-to-Reach-USD-1897-Million-by-2027-Fior-Markets.html.

23. Galbadage T, Peterson BM, Gunasekera RS. Does COVID-19 Spread Through Droplets Alone? 2020;8(163).

24. van Doremalen N, Bushmaker T, Morris DH, et al. Aerosol and Surface Stability of SARS-CoV-2 as Compared with SARS-CoV-1. 2020;382(16):1564-1567.

25. Perencevich EN, Diekema DJ, Edmond MB. Moving Personal Protective Equipment Into the Community: Face Shields and Containment of COVID-19. JAMA. 2020.

26. A tale of two contact-tracing apps: Lessons from Australia and New Zealand. (2020, May 22). Retrieved from https://www.aei.org/technology-and-innovation/a-tale-of-two-contact-tracing-apps-lessons-from-australia-andnew-zealand/.

27. Soalan Lazim App MySejahtera Covid-19 | My Sejahtera. (n.d.). Retrieved June 4, 2020, from https://mysejahtera.malaysia.gov.my/FAQ_en/.

28. Lee D, Lee J. Testing on the Move South Korea's rapid response to the COVID-19 pandemic. Transportation Research Interdisciplinary Perspectives. 2020:100111.

29. Riyaz, K. (2020, May 8). Virus cases in foreigners rise in Singapore, Malaysia. Retrieved from https://www.aa.com.tr/en/asia-pacific/virus-cases-in-foreigners-rise-in-singapore-malaysia/1833782.

30. Lee E, Mohd Esa NY, Wee TM, Soo Cl. Bonuses and pitfalls of a paperless drive-through screening and COVID-19: A field report. Journal of Microbiology, Immunology and Infection. 2020.

31. Kelly, J., 2020. Here Are The Companies Leading The Work-From-Home Revolution. [online] Forbes. Available at: <https://www.forbes.com/sites/jackkelly/2020/05/24/the-work-from-home-revolution-is-quickly-gainingmomentum/\#69f42e041848> [Accessed 28 May 2020].

32. Detrixhe, J. (2020, May 28). Why the US unemployment rate is so much higher than Germany's. Retrieved from https://qz.com/1861408/why-us-unemployment-is-higher-than-germany/.

\section{Figures}




\section{CLINICAL CATEGORY}

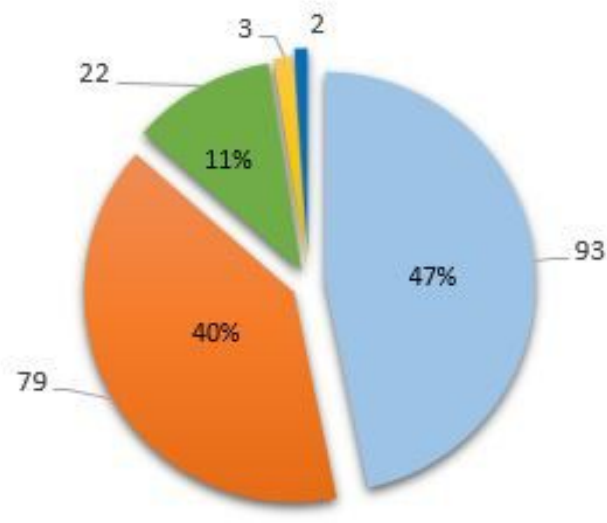

in Category 1 a Category 2 ategory 3

nCategory 4 a Category 5

\section{Figure 1}

Clinical category of our total cohort of COVID-19 patients with percentages $(n=199)$

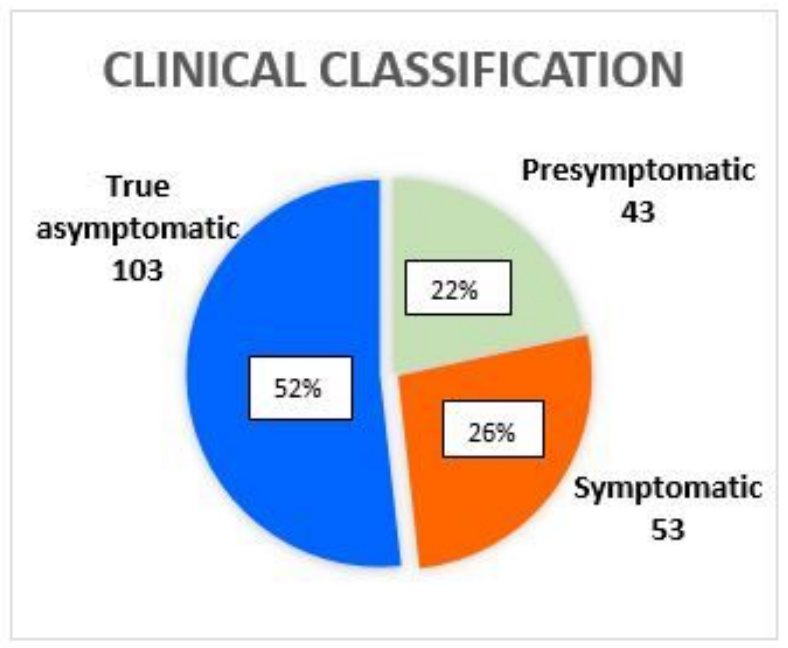

\section{Figure 2}

Clinical classification of our total cohort of COVID-19 patients with percentages $(n=199)$ 